\title{
Enhancement of Artemisinin in Artemisia annua L. through Induced Mutation
}

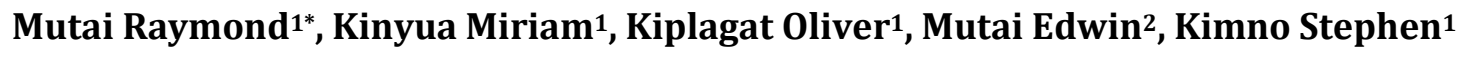 \\ ${ }^{1}$ Department of Biotechnology, School of Agriculture, University of Eldoret, Eldoret, Kenya \\ ${ }^{2}$ Department of Biological Sciences, School of Science, University of Eldoret, Eldoret, Kenya \\ Email: *raymutais@gmail.com
}

Received 12 December 2015; accepted 26 December 2015; published 30 December 2015

Copyright (C) 2015 by authors and OALib.

This work is licensed under the Creative Commons Attribution International License (CC BY).

http://creativecommons.org/licenses/by/4.0/

(c) (i) Open Access

\section{Abstract}

Artemisia annua is the source of artemisinin, an antimalarial drug which is effective against multidrug-resistant strains of plasmodium, the malarial parasite. Malaria has serious effects on morbidity and mortality thus negatively impacting on agricultural production and food security. Although artemisinin has been found to be a useful medicine; its production is very low in comparison with what is actually needed to treat the worldwide threat of malaria. On the other hand, the lower content $(0.01 \%-0.8 \%$, dry weight) of artemisinin found in leaves and flowers of $A$. annua has seriously limited its commercialization. Currently there are only two varieties of $A$. annua present in Kenya; hence there is a need to increase its diversity. The objective of the current study was to determine the effect of mutation on agronomical traits and artemisinin production by parents and mutant $\left(\mathrm{M}_{2}\right)$ A. annua plants in Kenya Agricultural and Livestock Research Organisation (KALRO) Njoro and the University of Eldoret (UoE). Seeds of two varieties of Artemesia annua varartemis and varanamed were sent to Vienna Austria for irradiation at the International Atomic Energy Agency (IAEA) at a dosage of 150 gray. The $M_{1}$ seeds were multiplied at the University of Eldoret farm. The harvested seeds were planted in replicate at the University of Eldoret and Njoro (KALRO). The results showed that mutation had significant effect on agronomical traits (P-value < 0.001). Mutant varieties and lines showed wide variation in terms of agronomical traits (crown length, stem length, plant height and stem diameter) and yield of artemisinin. The following lines showed superiority in artemisinin production; Artemis line 1, 2 and 9 with an average mean of $58.843,58.393$ and $69.192 \mu \mathrm{g} / \mathrm{l}$, respectively while Anamed line 2, 3, 5 and 8 with an average of $56.268,51.704,53.557$ and $54.448 \mu \mathrm{g} / \mathrm{l}$, respectively. The effect of mutation on both agronomical traits and production of the artemisinin content appeared to occur randomly and was also dependent on environmental factors in the different ecological zones. Higher means in agronomical traits was observed in UoE while production of artemisinin content was enhanced in Njoro. The artemisinin yield in $A$. annua crops was negatively correlated with leaf traits, shoot and stem characteristics. Leaf traits had positive correlations with shoot and stem characteristics. It is recommended that superior lines be advanced in generations for further stability and evaluation of its efficacy in treatment of malaria.

\footnotetext{
${ }^{*}$ Corresponding author.
}

How to cite this paper: Raymond, M., Miriam, K., Oliver, K., Edwin, M. and Stephen, K. (2015) Enhancement of Artemisinin in Artemisia annua L. through Induced Mutation. Open Access Library Journal, 2: e2189.

http://dx.doi.org/10.4236/oalib.1102189 


\title{
Keywords
}

\section{Artemisinin, Mutation, Varieties, Agronomical Traits}

\author{
Subject Areas: Agricultural Science, Biotechnology, Plant Science
}

\section{Introduction}

Artemisia annua L. is also referred to as annual wormwood, sweet wormwood and sweet annie. It is a highly aromatic annual herb of Asiatic and eastern European origin. It is widely dispersed throughout the temperate region [1]. A. annua is the source of artemisinin, an antimalarial drug which is effective against multidrug resistant strains of plasmodium, the malarial parasite [2] [3]. Artemisinin and its derivatives have been found to be effective against all stages of resistant strains of Plasmodium falciparum [4] [5]. Although it has been found to be a useful medicine; its production is very low in comparison with what is actually needed to treat the worldwide threat of malaria. The World Health Organization (W.H.O) recommends Artemisinin based combination therapys (ACTs) in regions where multi drug resistance is prevalent [6]. In line with this, a large proportion of the government of Kenya's annual budget is allocated to the importation of ACTs. These costs could however be reduced by production of artemisinin from A. annua. A substantial increase in the content of artemisinin is required to make artemisinin available on a large scale. The lower content of artemisinin found in leaves and flowers of A. annua has seriously limited its commercialization [7] [8]. This presents a problem because of the very low production levels of artemisinin in the native plant. Mutational breeding has an important role for the improvement of yield and quality traits of the crops including medicinal plants [9] [10]. Mutation breeding is the genetic improvement of crop plants for various characters through the use of induced mutation. The main strategy in mutation based breeding is to upgrade the well adapted plant varieties by improving a few desirable major yield and quality traits [11] [12]. Besides the increased yield and enhanced quality of novel varieties included, several other traits such as breeding, improved harvest index from heterosis in hybrid cultivars, response to increased agronomic inputs and consumer preference are enhanced. Mutational breeding will result in increased artemisinin in A. annua which will give insight to possibly steer drug formulation for treatment and control of malaria and as well as have a positive economic impact to Kenya. The objective of the current study was to determine the effect of mutation on agronomical traits and Artemisinin production by parents and mutant $\left(\mathrm{M}_{2}\right) A$. annua plants in Kenya Agricultural and Livestock Research Organisation (KALRO) Njoro and the University of Eldoret (UoE).

\section{Materials and Methods}

\subsection{Site Description}

The study was conducted at Kenya Agricultural and Livestock Research Organisation (KALRO) Njoro and the University of Eldoret (UoE), $\left(0^{\circ} 30^{\prime} 0^{\prime \prime}\right.$ North, $35^{\circ} 15^{\prime} 0^{\prime \prime}$ East), $10 \mathrm{Km}$ from Eldoret town, in Uasin Gishu county, Kenya. It is located at an altitude of $1280 \mathrm{~m}$ above sea level; it consists primarily of an agro-ecological zone Lower Highland 3 (LH3). The University of Eldoret receives a unimodial rainfall which begins in March. The average annual range is between $900 \mathrm{~mm}$ and $1100 \mathrm{~mm}$ and mean annual temperature of $16.6^{\circ} \mathrm{C}$. The soils are shallow, ferralsol, well drained, non humiccambisols with low nutrient availability and moisture storage [13].

\subsection{Experimental Design}

\subsubsection{Plant Materials}

One gram of $\mathrm{M}_{0}$ (non-mutated seeds) of both Artemisia annua varartemis and Artemisia annua varanamed, obtained from ICRAF (World Agroforestry Centre, Nairobi), Kenya, were sent to International Atomic Energy Agency (IAEA) in Vienna Austria and subjected to gamma radiation at an irradiation dose of 150 gy (gray) to obtain $\mathrm{M}_{1}$ (mutated seeds that gives rise to the first generation of mutants). This is the first generation of irradiated seeds which was designed as $\mathrm{M}_{1}$. 


\subsubsection{Determination of $\mathrm{LD}_{50}$}

Irradiated seeds were sown under controlled conditions. Germination rates of the seeds were determined from the $7^{\text {th }}$ day after sowing until the $14^{\text {th }}$ day. The seeds were exposed to irradiation of between 50 gy and 450 at intervals of 50 . The effective dose was determined by measuring the dose that decreases germination rate down to $50 \%$ hence 150 gy.

\subsubsection{Multiplication and Selection}

The nurseries were prepared in the greenhouse and the seeds spread and left uncovered according to the world agroforestry Centre recommendations. The seeds germinated after 7 days although some could be seen germinating after 4 days. The seedlings were transplanted in poly-tubes (75 by 140 by $37 \mathrm{~mm}$ ) after the appearance of four leaves. After 7 weeks the seedlings were hardened off through the exposure to full sunlight for a week before transplanting to the experimental field site. The field site was prepared in advanced. The seedlings were planted at spacing of $1 \mathrm{~m}$ by $1 \mathrm{~m}$ between and within row. The field were kept weed free until the Artemisia were fully established. At harvest the chimeric and deformed plants were not selected. The harvested seeds from each plant were put into individual envelope and labeled. One group was planted at the university of Eldoret experimental field while the corresponding groups were planted at Njoro. The seeds from each plant were designated as $\mathrm{M}_{2}$.

\subsubsection{Experimental Procedure}

The nurseries were prepared in the greenhouse and the seeds spread and left uncovered. The seeds germinated after 7 days. The seedlings were transplanted in poly-tubes ( 75 by 140 by $37 \mathrm{~mm}$ ) after the appearance of four leaves. After 7 weeks the seedlings were hardened off through the exposure to full sunlight for a week before transplanting to the experimental field site. A field experiment was then established. The land was disc ploughed suitable for A. annua planting. The experiment was laid out in a randomized completely block design (RCBD) replicated three times. The spacing between and within plants was $1 \mathrm{~m}$ by $1 \mathrm{~m}$. The experimental units were separated by $1.5 \mathrm{~m}$ by $1.5 \mathrm{~m}$ wide alleyways within and between blocks, respectively. The fields were kept weed free until the Artemisia were fully established.

\subsubsection{Data Collection}

The agronomic traits and artemisinin content for each of the $\mathrm{M}_{2}$ plants in the different zones were measured 4 months after establishment. For artemisinin analysis the leaves found in the upper parts of the A. annua plant, were harvested just before full flowering.

\subsection{Artemisinin Extraction and Sample Preparation}

Leaves were obtained from the plant during the flowering stage and air dried at $27^{\circ} \mathrm{C}$. merceration was performed in Erlenmeyer with a magnetic stirrer speed of $700 \mathrm{rpm}$ using ethanol as a solvent. This process was done many times until the methanol layer was colorless. The extract was then evaporated using a rotavapor vacuum at a temperature of $40^{\circ} \mathrm{C}$ until the extract volume was $100 \mathrm{ml}$.

\subsection{Spectrophotometric Quantification of Artemisinin}

Spectrophotometric quantification was performed using slightly modified methods described by Sreeviydaand Narayana [14].

\subsubsection{Reagents}

All solutions were prepared with double distilled water. Chemicals were of analytical grade. Hydrochloric acid (5M), Potassium iodide (2\%), Sodium acetate (2 M) and 0.001\% solution of Safranin were used.

\subsubsection{Standard Artemisinin (ART) Solution}

A $1000 \mu \mathrm{g} \cdot \mathrm{ml}^{-1}$ standard drug solution was prepared by dissolving $0.1 \mathrm{~g}$ of ART in ethanol and diluting to the mark in $100 \mathrm{ml}$ calibrated flask.

\subsubsection{Method for Determination of ART}

Different aliquots $(16.0$ - $112.0 \mu \mathrm{g} / \mathrm{l})$ were prepared. $10 \mathrm{ml}$ of standard ART and sample extract was transferred 
to calibrated flasks by means of micro burette, then $1 \mathrm{ml}$ each of $2 \%$ potassium iodide and 5 M HCL was then added followed by $2 \mathrm{ml}$ of $2 \mathrm{M}$ sodium acetate solution then the mixture was shaken for 5 mins. The contents were then diluted to the mark with distilled water and mixed well. The absorbance of each solution was then measured at $521 \mathrm{~nm}$ against the corresponding reagent blank. The reagent blank was prepared by replacing the analyte (ART) solution with distilled water. The absorbance of the corresponding to the bleached color, which in turn corresponds to the analyte (ART) concentration, was obtained by subtracting the absorbance of the blank solution by that of the test solution.

\subsection{Data Analysis}

The data was analyzed using Genstat $13^{\text {th }}$ edition and means separated using Tukeys Multiple Range Test where applicable. Correlation was done using Genstat Pearson correlation Coefficients.

\section{Results}

\subsection{Effects of Mutation on Agronomical Traits at $\mathbf{M}_{2}$}

There was significant difference in crown length, plant height, and stem diameter between parent and mutant plant sat $\mathrm{P}<0.001$ at UoE study site (Table 1). In UoE Artemis plants, there was significant difference in crown

Table 1. Comparison of means for Agronomical characteristics in parent and mutant plants in two plant varieties at UoE and Njoro sites (95.0 percent SED intervals, P-value 0.001).

\begin{tabular}{|c|c|c|c|c|}
\hline \multirow{2}{*}{ Traits } & \multirow{2}{*}{ Site } & \multicolumn{2}{|c|}{ Mean/Variety (units in cm) } & \multirow{2}{*}{ P-value } \\
\hline & & Par Artemis & Mutant Artemis & \\
\hline \multirow{2}{*}{ Crown length } & UoE & $67.41 \pm 6.39$ & $105.96 \pm 6.39$ & $<0.001$ \\
\hline & Njoro & $71.77 \pm 5.15$ & $84.27 \pm 5.15$ & 0.017 \\
\hline \multirow{2}{*}{ Stem length } & UoE & $18.59 \pm 14.17$ & $75.83 \pm 14.17$ & $<0.001$ \\
\hline & Njoro & $42.53 \pm 12.73$ & $62.80 \pm 12.73$ & 0.019 \\
\hline \multirow{2}{*}{ Plant height } & UoE & $17.83 \pm 1.48$ & $15.48 \pm 1.48$ & 0.115 \\
\hline & Njoro & $98.39 \pm 7.50$ & $116.38 \pm 7.50$ & 0.018 \\
\hline \multirow{2}{*}{ Branches } & UoE & $21.00 \pm 4.61$ & $27.39 \pm 4.61$ & 0.168 \\
\hline & Njoro & $18.21 \pm 4.45$ & $31.72 \pm 4.45$ & 0.003 \\
\hline \multirow{3}{*}{ Stem diameter } & UoE & $1.84 \pm 0.21$ & $3.00 \pm 0.21$ & $<0.001$ \\
\hline & Njoro & $2.00 \pm 0.15$ & $2.20 \pm 0.15$ & 0.179 \\
\hline & & Par Anamed & Mutant Anamed & \\
\hline \multirow{2}{*}{ Crown length } & UoE & $77.94 \pm 6.39$ & $127.62 \pm 6.39$ & $<0.001$ \\
\hline & Njoro & $83.88 \pm 5.73$ & $80.864 \pm 5.73$ & 0.600 \\
\hline \multirow{2}{*}{ Stem length } & UoE & $29.82 \pm 14.86$ & $102.65 \pm 14.86$ & $<0.001$ \\
\hline & Njoro & $44.41 \pm 10.23$ & $46.03 \pm 10.23$ & 0.875 \\
\hline \multirow{2}{*}{ Plant height } & UoE & $103.25 \pm 5.98$ & $145.56 \pm 5.98$ & $<0.001$ \\
\hline & Njoro & $112.52 \pm 6.75$ & $111.15 \pm 6.75$ & 0.839 \\
\hline \multirow{2}{*}{ Branches } & UoE & $24.47 \pm 4.82$ & $35.52 \pm 4.82$ & 0.022 \\
\hline & Njoro & $29.18 \pm 4.22$ & $35.04 \pm 4.22$ & 0.170 \\
\hline \multirow{2}{*}{ Stem diameter } & UoE & $2.11 \pm 0.17$ & $3.14 \pm 0.17$ & $<0.001$ \\
\hline & Njoro & $2.24 \pm 0.16$ & $2.11 \pm 0.16$ & 0.410 \\
\hline
\end{tabular}


length, stem length and Stem diameter in Artemis plants with means of $67.41 \pm 6.39,18.59 \pm 14.17$ and $1.84 \pm$ 0.21 for parent plants and $105.96 \pm 6.39,75.83 \pm 14.17$ and $3.00 \pm 0.21$ for mutant plants respectively, while in Anamed plants there was significant difference in crown length, stem length, Plant height and Stem diameter with means of $77.94 \pm 6.39,29.82 \pm 14.86,103.25 \pm 5.98$ and $2.11 \pm 0.17$ for parent plants and means of 127.64 $\pm 6.39,102.65 \pm 14.86,3.14 \pm 0.17$ and $145.56 \pm 5.98$ for mutant plants respectively. None of the agronomical characteristics analyzed were significantly different at Njoro in the two plant varieties.

The means of agronomical characteristics per plant line at UoE and Njoro sites $(\mathrm{P}<0.001)$ are shown in Table 2. There was significant difference in stem diameter of Artemis lines at UoE only. Line 2 had the highest mean of 3.9 while Line 12 had the lowest mean of 2.2. In UoE Anamed lines, there was significant difference in

Table 2. Means of agronomical characteristics per plant line in UoE and Njoro sites (95.0 percent SED intervals, P-value 0.001).

\begin{tabular}{|c|c|c|c|c|c|c|c|c|c|c|}
\hline \multirow{2}{*}{$\begin{array}{l}\text { Artemi } \\
\text { Lines }\end{array}$} & \multicolumn{5}{|c|}{ Njoro (units in cm) } & \multicolumn{5}{|c|}{ UoE (units in $\mathrm{cm}$ ) } \\
\hline & C. Lgt & S. Lgt & P. hgt & branch & s dter & C. Lgt & S. Lgt & P. hgt & branch & s dter \\
\hline Parents & 71.7 & 42.5 & 98.4 & 18.2 & 2.0 & 67.4 & 18.6 & 17.8 & 21.0 & $1.8 \mathrm{c}$ \\
\hline 1 & 83.4 & 68.8 & 109.6 & 33.1 & 2.6 & 102.4 & 119.4 & 137.4 & 41.3 & $3.5 a$ \\
\hline 2 & 85.7 & 38.0 & 103.6 & 29.3 & 2.0 & 109.9 & 54.1 & 132.6 & 24.8 & $3.0 \mathrm{~b}$ \\
\hline 3 & 83.0 & 52.1 & 103.0 & 30.0 & 2.5 & 99.2 & 49.8 & 132.2 & 20.9 & $3.1 b$ \\
\hline 4 & 70.5 & 48.6 & 106.5 & 24.0 & 1.8 & 102.9 & 56.3 & 136.6 & 27.1 & $2.6 b$ \\
\hline 5 & 85.6 & 51.3 & 116.1 & 32.6 & 1.8 & 113.3 & 95.4 & 136.8 & 31.4 & $2.6 b$ \\
\hline 6 & 87.7 & 60.5 & 122.7 & 34.7 & 2.1 & 97.4 & 98.0 & 137.8 & 30.7 & $2.4 c$ \\
\hline 7 & 79.4 & 79.2 & 122.4 & 31.8 & 2.5 & 105.1 & 98.7 & 122.0 & 34.6 & $2.7 \mathrm{~b}$ \\
\hline 8 & 90.4 & 81.8 & 130.6 & 38.3 & 2.2 & 91.1 & 91.6 & 146.9 & 27.4 & $2.2 \mathrm{c}$ \\
\hline 9 & 93.4 & 75.9 & 124.0 & 37.3 & 2.5 & 125.9 & 51.0 & 145.1 & 18.7 & $3.9 a$ \\
\hline 10 & 88.9 & 48.0 & 110.1 & 31.7 & 2.4 & 100.2 & 74.9 & 105.4 & 32.8 & $3.1 b$ \\
\hline 11 & 88.0 & 65.1 & 113.9 & 26.4 & 1.8 & 122.8 & 93.6 & 147.7 & 31.0 & $3.7 a$ \\
\hline 12 & 66.7 & 69.1 & 123.4 & 25.1 & 2.2 & 102.0 & 36.8 & 151.7 & 11.4 & $3.0 \mathrm{~b}$ \\
\hline P-value & 0.247 & 0.772 & 0.266 & 0.757 & 0.02 & 0.123 & 0.048 & 0.003 & 0.052 & $<0.001$ \\
\hline Anam & & & Njoro & & & & & UoE & & \\
\hline Parents & 83.9 & 44.0 & 112.2 & 29.2 & $2.2 \mathrm{~b}$ & $77.9 \mathrm{~d}$ & 29.8 & 103.3d & 24.5 & 2.1 \\
\hline 1 & - & - & - & - & - & - & - & - & - & - \\
\hline 2 & 74.4 & 33.5 & 116.2 & 38.7 & $1.7 \mathrm{c}$ & $146.1 \mathrm{a}$ & 122.7 & $165.4 \mathrm{a}$ & 43.1 & 3.2 \\
\hline 3 & 86.5 & 76.9 & 102.1 & 39.6 & $2.1 \mathrm{~b}$ & 120.7b & 106.0 & 136.0b & 36.3 & 3.3 \\
\hline 4 & 77.9 & 52.1 & 120.8 & 33.6 & $2.1 b$ & 120.7b & 111.3 & 147.6b & 39.3 & 3.3 \\
\hline 5 & 79.2 & 27.8 & 117.8 & 43.6 & $2.1 \mathrm{~b}$ & 142.1a & 122.4 & 159.6a & 36.8 & 3.9 \\
\hline 6 & 89.4 & 57.2 & 114.9 & 32.9 & $2.1 b$ & 148.6a & 102.8 & $146.9 \mathrm{~b}$ & 37.1 & 2.9 \\
\hline 7 & 68.8 & 35.1 & 97.9 & 21.8 & $1.6 \mathrm{c}$ & 107.8c & 75.8 & 140.6b & 27.3 & 2.9 \\
\hline 8 & 85.4 & 40.7 & 104.0 & 29.2 & $2.7 \mathrm{a}$ & 109.1c & 73.1 & $128.4 \mathrm{c}$ & 29.4 & 2.8 \\
\hline 9 & - & - & - & - & - & 126.1b & 107.2 & 139.9b & 36.3 & 2.8 \\
\hline $\mathrm{P}$-value & 0.519 & 0.04 & 0.162 & 0.06 & $<0.001$ & $<0.001$ & 0.49 & $<0.001$ & 0.648 & 0.003 \\
\hline
\end{tabular}

Means followed by the same letter in a column are not significantly different. 
crown length and plant height. In crown length, line 5 had the highest mean of 148.6 while line 6 had the lowest mean of 107.8. In plant height, line 1 had the highest mean of 165.4 while line 7 had the lowest mean of 128.4. In Njoro Anamed lines, there was a significant difference in stem diameter only with line 8 having highest mean of 2.7 while line 7 had the lowest mean of 1.6.

\subsection{Comparison of Artemisinin Production by Parents and Mutant ( $\left.\mathbf{M}_{2}\right)$ Plants}

The results for means of comparison of artemisinin production between UoE and Njoro sites (P-value 0.001) are shown in Table 3. There was significant difference in artemisinin production between the two sites in both mutant varieties (Artemis and Anamed). In Artemis, Njoro had the highest mean of $44.92 \pm 2.39$ while UoE had the lowest mean of $24.93 \pm 2.39$. In mutant Anamed, Njoro had the highest mean of $43.67 \pm 3.31$ while UOE had the lowest mean of $25.71 \pm 3.31$. There was no significant difference in artemisinin production by parents of the two varieties (Artemis and Anamed) between the two sites.

There was significant difference in artemisinin production by Artemis and Anamed at Njoro at $\mathrm{P}<0.001$ (Table 4). Mutant plants had the highest mean of $43.166 \pm 5.754$ and $45.484 \pm 6.323$ while parent plants had the lowest mean of $22.355 \pm 5.754$ and $22.805 \pm 6.323$ for Artemis and Anamed respectively.

The results for means of artemisinin production per plant line in UoE and Njoro sites $(\mathrm{P}<0.001)$ are shown in Table 5. There was significant difference in production of artemisinin by Artemis lines in Njoro only. Line 1 had the highest mean of 58.843 while Line 12 had the lowest mean of 25.949 for atemisinin production. In Anamed there was significant difference in production of artemisinin at both UoE and Njoro. At UoE, Line 2 had the highest mean of 39.200 while Line 5 had the lowest mean of 9.200; while at Njoro, Line 2 had the highest mean of 56.260 while Line 6 had the lowest mean of 20.190 .

\subsection{Correlation Analysis of Agronomical Traits and Artemisinin Production}

The estimated correlation among agronomical traits in mutant Artemis is represented in Table 6(a). There was a significant positive correlation between crown length, stem length and stem diameter; Stem length, plant height, number of branches and stem diameter; Leaf width and stem diameter; plant height, number of branches and stem diameter; and number of branches with stem diameter. Artemisinin production had a significant negative correlation with crown length, stem length, plant height and stem diameter.

Table 3. Means for comparison of artemisinin production between UoE and Njoro sites (95.0 percent SED intervals, P-value 0.001).

\begin{tabular}{cccc}
\hline Variety & $\begin{array}{c}\text { UoE mean } \pm \mathrm{SE} \\
(\text { Units in } \mu \mathrm{g} / \mathrm{l})\end{array}$ & $\begin{array}{c}\text { Njoro mean } \pm \mathrm{SE} \\
(\text { Units in } \mu \mathrm{g} / \mathrm{l})\end{array}$ & P-value \\
\hline Par Artemis & $21.80 \pm 2.04$ & $22.40 \pm 2.04$ & 0.783 \\
Artemis & $24.93 \pm 2.39$ & $44.92 \pm 2.39$ & $<0.001$ \\
Par Anamed & $23.70 \pm 2.00$ & $22.80 \pm 2.00$ & 0.644 \\
Anamed & $25.71 \pm 3.31$ & $43.67 \pm 3.31$ & $<0.001$ \\
\hline
\end{tabular}

Table 4. Comparison of Means for artemisinin production in parent and mutant plants in two plant varieties in UoE and Njoro sites (95.0 percent SED intervals, P-value 0.001).

\begin{tabular}{cccc}
\hline \multirow{2}{*}{ Site } & \multicolumn{2}{c}{ Mean/variety $($ units in $\mu \mathrm{g} / \mathrm{l})$} & \multirow{2}{*}{ P-value } \\
\cline { 2 - 3 } & Par Artemis & Mutant Artemis & \\
\hline UoE & $21.788 \pm 2.583$ & $24.925 \pm 2.583$ & 0.227 \\
Njoro & $22.355 \pm 5.754$ & $43.166 \pm 5.754$ & $<0.001$ \\
\hline UoE & Par Anamed & Mutant Anamed & 0.375 \\
Njoro & $22.665 \pm 3.636$ & $25.908 \pm 3.636$ & $<0.001$ \\
\hline
\end{tabular}


Table 5. Means of artemisinin production per plant line in UoE and Njoro sites (95.0 percent SED intervals, P-value 0.001).

\begin{tabular}{|c|c|c|c|c|c|}
\hline \multirow{3}{*}{$\begin{array}{l}\text { Line } \\
\text { Parents }\end{array}$} & \multirow{2}{*}{\multicolumn{2}{|c|}{$\begin{array}{c}\text { Artemis (units in } \mu \mathrm{g} / \mathrm{l} \text { ) } \\
\text { UoE Njoro }\end{array}$}} & \multirow{3}{*}{$\begin{array}{c}\text { Line } \\
\text { Parents }\end{array}$} & \multirow{2}{*}{\multicolumn{2}{|c|}{$\begin{array}{c}\text { Anamed (units in } \mu \mathrm{g} / \mathrm{l} \text { ) } \\
\text { UoE Njoro }\end{array}$}} \\
\hline & & & & & \\
\hline & 21.800 & $22.400 \mathrm{~d}$ & & $25.700 \mathrm{~b}$ & $43.700 \mathrm{a}$ \\
\hline 1 & 23.565 & $58.843 b$ & 1 & - & - \\
\hline 2 & 20.037 & 58.393b & 2 & 23.300b & $56.268 \mathrm{a}$ \\
\hline 3 & 28.636 & $48.648 c$ & 3 & $39.200 a$ & $51.704 a$ \\
\hline 4 & 30.143 & $47.293 c$ & 4 & $25.900 \mathrm{~b}$ & $27.009 \mathrm{~b}$ \\
\hline 5 & 17.274 & $43.253 c$ & 5 & $24.500 \mathrm{~b}$ & $53.557 \mathrm{a}$ \\
\hline 6 & 25.408 & 29.774d & 6 & $9.200 \mathrm{c}$ & $20.192 b$ \\
\hline 7 & 19.898 & 39.327c & 7 & $27.600 \mathrm{~b}$ & $45.401 \mathrm{a}$ \\
\hline 8 & 25.97 & $47.578 c$ & 8 & 28.800b & $54.448 \mathrm{a}$ \\
\hline 9 & 24.035 & 69.192a & 9 & $27.200 \mathrm{~b}$ & - \\
\hline 10 & 30.076 & $41.843 c$ & 10 & - & - \\
\hline 11 & 29.526 & $44.222 \mathrm{c}$ & 11 & - & - \\
\hline 12 & 24.748 & 25.949d & 12 & - & - \\
\hline P-value & 0.144 & $<0.001$ & & 0.001 & $<0.001$ \\
\hline
\end{tabular}

Means followed by the same letter in a column are not significantly different.

The estimated correlation among agronomical traits in mutant Anamed is represented in Table 6(b). There was a significant positive correlation between crown length, stem length, leaf width, plant height, number of branches and stem diameter; stem length, leaf width, plant height, number of branches and stem diameter; plant height, number of branches and stem diameter; number of branches with stem diameter. Artemisinin production had a significant negative correlation with crown length, stem length, leaf length and plant height.

\section{Discussion}

\subsection{Effects of Mutation on Agronomical Traits and Production of Artemisinin Content}

In the present study mutant varieties and lines showed wide variation in terms of agronomical traits (crown Length, Stem length, Plant height and Stem diameter) and yield of artemisinin content. A total of 108 Artemis and 72 Anamed plants were planted at UoE and KALRO Njoro sites respectively. At UoE site, only 3 plants in each variety (Artemis and Anamed) had a production of more than $60 \mu \mathrm{g} / \mathrm{ml}$ Artemisin concentration while at Njoro, 46 Artemis and 19 Anamed plants had a production of more than $60 \mu \mathrm{g} / \mathrm{l}$ artemisin concentration. Parent Artemis had an average artemisinin production of 21.788 at UoE and 22.355 at Njoro while parent Anamed plants had an average artemisinin production of 22.665 at UoE and 22.805 at Njoro. Concentrations levels of Artemisinin that are above $60 \mu \mathrm{g} / \mathrm{l}$, is the commercially viable level [15] [16]. In some cases for example, mutant plants indicated higher performance in terms of agronomical characteristics and/or artemisinin production, similarly some lines showed superiority over other mutant lines and control (parent plants) within and/or between the two agroeconomical zones where the study was undertaken. The following lines showed superiority in artemisinin production; Artemis line 1, 2 and 9 with an average mean of 58.843, 58.393 and 69.192 respectively while Anamed line 2, 3, 5 and 8 with an average of 56.268, 51.704, 53.557 and 54.448 respectively. Similar results have been observed by Mucci [17] in wheat. Mutational breeding has important role for improvement of yield and quality of crops including medicinal plants for example Koobkokkruad et al. [12] [18] used gamma irradiation for enhancement of artemisininin A. annua. There was significant difference in production of artemisinin by Artemis lines at Njoro site only where Line 1 had the highest mean of 58.843 and Line 12 with the lowest mean of 25.949 while in Anamed lines, significant difference in production of artemisinin was observed 
Table 6. (a) Correlations analysis of agronomical traits and artemisininin mutant artemis; (b) Correlations analysis of agronomical traits and artemisininin mutant anamed.

(a)

\begin{tabular}{|c|c|c|c|c|c|c|c|c|}
\hline & 1 & 2 & 3 & 4 & 5 & 6 & 7 & 8 \\
\hline 1) Crown length & - & & & & & & & \\
\hline 2) Stem length & $0.1563^{* *}$ & - & & & & & & \\
\hline 3) Leaf length & -0.0372 & 0.0696 & - & & & & & \\
\hline 4) Leaf width & 0.0713 & 0.043 & $0.1493^{* *}$ & - & & & & \\
\hline 5) Plant height & $0.5501^{*}$ & $0.3718^{* *}$ & 0.008 & 0.0745 & - & & & \\
\hline 6) No. branches & 0.0797 & $0.7508^{*}$ & 0.0872 & -0.0208 & $0.2578^{* *}$ & - & & \\
\hline 7) Stem diam & $0.6389^{*}$ & $0.2322^{* *}$ & 0.0333 & $0.1534^{* *}$ & $0.5038^{*}$ & $0.1223^{* *}$ & - & \\
\hline 8) Artemisinin & $-0.2828^{* *}$ & $-0.1492^{* *}$ & 0.0709 & 0.0164 & $-0.3642^{* *}$ & -0.0701 & $-0.3599^{* *}$ & - \\
\hline
\end{tabular}

*** Significant at $\mathrm{P}<0.05$; ${ }^{*}$ Significant at $\mathrm{P}<0.01$.

(b)

\begin{tabular}{|c|c|c|c|c|c|c|c|c|}
\hline & 1 & 2 & 3 & 4 & 5 & 6 & 7 & 8 \\
\hline 1) Crown length & - & & & & & & & \\
\hline 2) Stem length & $0.5588^{*}$ & - & & & & & & \\
\hline 3) Leaf length & 0.0307 & $0.1031^{* *}$ & - & & & & & \\
\hline 4) Leaf width & $0.2003^{* *}$ & 0.0380 & 0.0497 & - & & & & \\
\hline 5) Plant height & $0.7896^{*}$ & $0.5359^{*}$ & 0.0630 & $0.1203^{* *}$ & - & & & \\
\hline 6) No. branches & $0.2256^{* *}$ & $0.6852^{*}$ & -0.0139 & 0.0235 & $0.2212^{* *}$ & - & & \\
\hline 7) Stem diam & $0.7204^{*}$ & $0.5273^{*}$ & 0.0912 & $0.2202^{* *}$ & $0.6384^{*}$ & $0.1679 * *$ & - & \\
\hline 8) Artemisinin & $-0.2838^{* *}$ & $-0.2217^{* *}$ & $-0.1601^{* *}$ & -0.0167 & $-0.3127^{* *}$ & -0.0499 & $-0.1881^{* *}$ & - \\
\hline
\end{tabular}

${ }^{* *}$ Significant at $\mathrm{P}<0.05$; ${ }^{*}$ Significant at $\mathrm{P}<0.01$.

at the two study sites. At UoE, Line 2 had the highest mean of 39.2 while Line 5 had the lowest mean of 9.2; while at Njoro, Line 2 had the highest mean of 56.26 while Line 6 had the lowest mean of 20.19 (Table 5). The changes that were seen could have been due to the effect of mutation and judging from the results, the mutation could be variety and environmentally dependent. Many authors also agree that observed characteristics are dependent on environmental factors [19] because the phenotype is the sum of factors genetic and environmental. This result is consistent with the findings of Cox [20] and Singh [21] who reported that artemisinin content is influenced by genetic factors and therefore re arrangement of the gene sequences induced by mutation resulted in increase in artemisinin content production in some cases and a total decrease in others. Such unpredictable results may be due to random mutations at different loci in the genome [22]. The physical mutagen gamma rays and its dose LD50 enhanced artemisinin content production from an average of $23.7 \mu \mathrm{g} / \mathrm{l}$ in original non irradiated seeds to 44.920 in irradiated seeds. Koobkokkruad et al. [13] also found out that the Physical mutagen gamma rays (LD 50) enhanced Artemisinin content from $0.03 \%$ to $0.70 \%$ (W/W). The pathway of artemisinin synthesis and the mechanism for its accumulation in leaves and inflorescences most probably determined the final artemisinin content in A. annua and the effect of other environmental factors such as nutrient availability might be incidental; a situation observed by Chalapathi et al. [23] [24]. In mutant Artemis plants, there was significant difference in crown length, plant height, and stem diameter while in mutant Anamed plants; there was significant difference in crown length, Stem length, plant height, and stem diameter. UoE showed higher means in all the parameters that were analyzed as compared to Njoro (Table 1). There was significant difference in artemisinin production between the two sites in both mutant varieties (Artemis and Anamed). In Artemis, Njoro 
had the highest mean of 44.92 while UoE had the lowest mean of 24.93. In Mutant Anamed, Njoro had the highest mean of 43.67 while UoE had the lowest mean of 25.71 (Table 3). There was no significant difference in artemisinin production by parents of the two varieties (Artemis and Anamed) between the two sites. Mutation may have been responsible for the difference in the agronomical characteristics and artemisinin production that was observed between the two agro-ecological zones and thus this is a clear indication that the changes induced by mutation is dependent on environmental influence. This observation was reinforced by the fact that in all the cases parents of both the plant varieties (Artemis and Anamed) did not show any significant difference in the agronomical characteristics analyzed and artemisinin production. Research conducted by Liu et al., [25] and Duke and Paul, [26] has also shown temperature and longitude to have an important bearing on the productivity of artemisia by producing high biomass and artemisinin content. Similar findings have been reported from Vietnam, where the artemisinin content was high in the high-altitude north than in the low-altitude south [27]. Also there is evidence that mutagens (radiations) stimulate metabolic activity of plants such as respiration glycolysis and oxidative phosphorylation [28] [29] and cytochrome oxidase and catalase activity which may ultimately influence and enhance synthesis of plant products [30] [31]. The lines exhibiting a total increase in artemisinin content and agronomical characteristics are the most suitable for high yield selection. The study also reveals that the pattern of plant height, plant spread, number of branches per plant and dry leaf yield largely correspond to that of artemisinin yield obtained. This corroborates findings by Laughlin [32] who stated that to achieve a commercially viable yield of artemisinin from A. annua, the evaluation of growth and yield components is important. This explains why evaluation of leaf biomass accumulation or production by A. annua was more important, since it is a precursor for higher artemisinin yield [33]. This implies that treatments that yield high morphological traits should be considered for higher artemisinin production.

\subsection{Correlation Analysis of Morphological Traits and Artemisinin Production}

The coefficients of correlations between all the pairs of variables are presented in Table 6(a) and Table 6(b). artemisinin yield in A. annua crops was negatively correlated with crown length, Stem length, leaf length, leaf width, Plant height, number of main branches and Stem diameter. Besides, leaf traits (crown length, leaf length, and leaf width) had positive correlations with stem characteristics (Stem Length, Plant height, number of main branches and Stem diameter). This indicates that proliferated plant growth did not favor artemisinin accumulation in the leaves. The highly significant positive correlation between leaf traits on one hand and shoot or stem traits on the other hand and negative correlation of agronomical characteristics with artemisinin content of leaves indicate that high yields of artemisinin were realized when crops produced least possible leaf and stem tissue growth. The results suggested that the rate of leaf biomass yield kept pace with the rate of crop growth parameters. The major organ in artemisinin production is the foliage. An experiment has confirmed positive correlation between plant growth traits and biomass yield of Artemisia [34]. Even though low proliferation of plant stem and leaf tissue resulted in higher Artemisinin content production, this could generally reduce the eventual expected yield and thus a plant with higher leaf yield will in turn have a higher leaf biomass which will then influence the total yield of Artemisinin. The significant positive correlation of plant height, plant spread, number of branches with leaf and biomass yield indicates the expected influence of these growth parameters on the yielding ability of A. annua. It can therefore be inferred that leaf biomass yield and artemisinin yield are largely dependent on the effect of the growth traits such as plant height and plant spread. Sushil, et al., [35] indicated that there is a linear relationship between leaf biomass accumulation and artemisinin yield and therefore indirect selection via high leaf biomass production would generally be effective for high artemisinin yield.

\section{Conclusions and Recommendations}

Mutant varieties and lines showed wide variation in terms of agronomical traits (crown length, stem length, plant height and stem diameter) and yield of artemisinin content. Some lines showed superiority over other mutant lines and control (parent plants). There was a significant difference in production of artemisinin by Artemis lines at Njoro site only where Line 1 had the highest mean of 58.843 and Line 12 with the lowest mean of 25.949 while in Anamed lines, significant difference in production of artemisinin was observed at the two study sites. At UoE, Line 2 had the highest mean of 39.2 while Line 5 had the lowest mean of 9.2; while at Njoro, Line 2 had the highest mean of 56.26 while Line 6 had the lowest mean of 20.19. The effect of mutation on both agronomical traits and production of the artemisinin content occurs randomly. Environmental factors appear to 
have an influence in expression of mutated genes related to agronomical characteristics and artemisinin production. Higher agronomical traits were observed in UoE while production of medicinal (artemisinin) content was enhanced in Njoro. Plants that produce artemisinin concentration $\geq 60 \mu \mathrm{g} / \mathrm{l}$ are economically viable. Artemisinin yield in A. annua crops was negatively correlated with leaf traits and stem characteristics. Leaf traits had positive correlations with stem characteristics. The study recommends that continual screening of Artemis lines 1, 2 and 9 and Anamed lines 2, 3, 5 and 8 be done and stabilization of these mutant lines through double haploid techniques and backcrossing to reduce the effects of mutations.

\section{Acknowledgements}

We are grateful to the International Atomic Energy Agency (IAEA) Vienna Austria for funding the project, World Agroforestry Centre (ICRAF), Nairobi, Kenya for providing the seeds and The University of Eldoret for hosting the project.

\section{References}

[1] Simon, J.E., Chadwick, A.F. and Craker, L.E. (1984) Herbs: An Indexed Bibliography, 1971-1980. The Scientific Literature on Selected Herbs, and Aromatic and Medicinal Plants of the Temperate Zone. Archon Books, Hamden.

[2] Luo, X.D. and Shen, C.C. (1987) The Chemistry, Pharmacology, and Clinical Applications of Artemisinin and Its Derivatives. Medicinal Research Reviews, 7, 29-52. http://dx.doi.org/10.1002/med.2610070103

[3] World Health Organization (2012) WHO Position Statement on Effectiveness of Non-Pharmaceutical Forms of Artemisia annua L. against Malaria. http://www.who.int/malaria/position_statement_herbal_remedy_artemisia_annua_l.pdf

[4] Balint, G. (2001) Artemisinin and Its Derivatives an Important New Class of Antimalarial Agents. Pharmacology \& Therapeutics, 90, 261-265. http://dx.doi.org/10.1016/S0163-7258(01)00140-1

[5] Ogwang, P.E., Ogwal, J.O., Kasasa, S., Olila, D., Ejobi, F., Kabasa, D. and Obua, C. (2012) Artemisia annua L. Infusion Consumed Once a Week Reduces Risk of Multiple Episodes of Malaria: A Randomized Trial in a Ugandan Community. Tropical Journal of Pharmaceutical Research, 13, 445-453.

[6] World Health Organization (WHO) (2004) Malaria Medicines and Supplies Service (MMSS). http://www.rollbackmalaria.org

[7] Van Agtmael, M.A., Eggelte, T.A. and van Boxtel, C.J. (1999) Artemisinin Drugs in the Treatment of Malaria: From Medicinal Herb to Registered Medication. Trends in Pharmacological Sciences, 20, 199-205. http://dx.doi.org/10.1016/S0165-6147(99)01302-4

[8] Willcox, M.L., Burton, S., Oyweka, R., Namyalo, R., Challand, S. and Lindsey, K. (2011) Evaluation and Pharmacovigilance of Projects Promoting Cultivation and Local Use of Artemisia annua for Malaria. Malaria Journal, 10, 84. http://dx.doi.org/10.1186/1475-2875-10-84

[9] Khan, S. and Al-Qurainy, F. (2010) Mutagenic Effect of Sodium Azide on Seed Germination of Eruca sativa (L.) Aust. Journal of Basic and Applied Sciences, 3, 3081-3087.

[10] Weathers, P.J. and Towler, M.J. (2012) The Flavonoids Castic in and Artemetin Are Poorly Extracted and Are Unstable in an Artemisia annua Tea Infusion. Planta Medica, 78, 1024-1026. http://dx.doi.org/10.1055/s-0032-1314949

[11] Ahloowalia, B.S., Maluszynki, M. and Nichterlein, K. (2004) Global Impact of Mutation Derived Varieties. Euphytica, 135, 187-204. http://dx.doi.org/10.1023/B:EUPH.0000014914.85465.4f

[12] Tomlekova, N.B. (2010) Induced Mutagenesis for Crop Improvement. Pl. Mut. Rep, 2, 4-27.

[13] Jaetzold, R. and Schimdt, H. (1983) Farm Management Handbook of Kenya. Vol. II. Natura Condition and Farm Management Information. Ministry of Agriculture, Kenya in Cooperation with German Agriculture Team (GAT) of the German Agency for Technical Cooperation (GTZ) Nairobi Kenya.

[14] Sreevidya, T.V. and Narayama, B. (2007) Spectrophotometric Determination of Artemisinin and Dihydroartemisinin. Indian Journal of Chemical Technology, 15, 59-62.

[15] Delabays, N., Benakis, A. and Collet, G. (1993) Selection and Breeding for High Artemisinin Yielding Strains of Artemisia annua. Acta Horticulturae, 330, 203-206. http://dx.doi.org/10.17660/ActaHortic.1993.330.24

[16] Abdin, M.Z., Israr, M., Rehman, R.U. and Jain, S.K. (2003) Artemisinin, a Novel Antimalarial Drug: Biochemical and Molecular Approaches for Enhanced Production. Planta Medica, 69, 289-299. http://dx.doi.org/10.1055/s-2003-38871

[17] Mucci, F. (1962) Notes on Seven Years of Observations of Wheat Types from Induced Mutation in c.v. Tavere. Ann. Pac. Sci. Agri. Protic, 28, 314-389.

[18] Koobkokkruad, T., Chochai, A., Kirdmanee, C. and De-Eknamkul, W. (2008) Effects of Low-Dose Gamma Irradiation 
Omartemesinin Content and Amorpha-4, 11-Diene Synthase Activity in Artemisia annua L. International Journal of Radiation Biology, 84, 878-884. http://dx.doi.org/10.1080/09553000802460131

[19] Khan, M.R., Qureshi, A.S., Hussain, S.A. and Ibrahim, M. (2005) Genetic Variability Induced by Gamma Irradiation and Its Modulation with Gibberelline Acid in M2 Generation of Chickpea (Cicer arietinum L.). Pakistan Journal of Botany, 37, 285-292.

[20] Cox, D. (1992) Fertilizing Herbs. The Herb, Spice and Medicinal Plant Digest, 10, 1-5.

[21] Singh, M. (2001) Effect of Nitrogen, Phosphorus and Potassium Nutrition on Herb, Oil and Artemisinin Yield of Artemisia annua under Semi-Arid Tropical Condition. Joint Milli-Arcsecond Pathfinder Survey, 23, 368-369.

[22] Barbacka, K. and Baer-Dubowska, W. (2011) Searching for Artemisinin Production Improvement in Plants and Microorganisms. Current Pharmaceutical Biotechnology, 12, 1743-1751. http://dx.doi.org/10.2174/138920111798376923

[23] Chalapathi, M.V., Vasundhara, M., Gangadhar Eswar Rao, G., Thimmegowda, S., Rao Prakash, E.V.S. and Devakumar, N. (2004) Influence of Integrated Nutrient Management on Yield of Davana (Artemisia pallens). Indian Perfumer, 48, 311-316.

[24] Simonnet, X., Quennoz, M. and Carlen, C. (2008) New Artemisia annua Hybrids with High Artemisinin Content. Acta Horticulturae, 769, 371-375. http://dx.doi.org/10.17660/actahortic.2008.769.52

[25] Liu, C.-Z., Guo, C., Wang, Y. and Ouyang, F. (2003) Factors Influencing Artemisinin Production from Shoot Cultures of Artemisia annua L. World Journal of Microbiology and Biotechnology, 19, 535-538. http://dx.doi.org/10.1023/A:1025158416832

[26] Duke, S.O. and Paul, R.N. (1993) Development and Fine Structure of Glandular Trichomes of Artemisia annua L. International Journal of Plant Sciences, 154, 107-118. http://dx.doi.org/10.1086/297096

[27] WHO (2003) Guidelines on Good Agricultural and Collection Practices (GACP) for Medicinal Plants. World Health Organization, 72 p. http://www.rbm.who.int/amd2003/amr2003 toc.htm

[28] Mergen, F. and Johnson, T.S. (1964) Effect of Ionizing Radiation in Seed Germination and Seedling Growth of Pinusrigida (MU). Radiation Botany, 4, 417-427. http://dx.doi.org/10.1016/S0033-7560(64)80009-0

[29] Farhi, M., Kozin, M., Duchin, S. and Vainstein, A. (2013) Metabolic Engineering of Plants for Artemisinin Synthesis. Biotechnology and Genetic Engineering Reviews, 29, 135-148. http://dx.doi.org/10.1080/02648725.2013.821283

[30] Brown, G.D. (2010) The Biosynthesis of Artemisinin (Qinghaosu) and the Phytochemistry of Artemisia annua L. (Qinghao). Molecule, 15, 7603-7698. http://dx.doi.org/10.3390/molecules15117603

[31] Soetaert, S.S.A., Van Neste, C.M.F., Vandewoestyne, M.L., Head, S.R., Goossens, A., Van Nieuwerburgh, F.C.W. and Deforce, D.L.D. (2013) Differential Transcriptome Analysis of Glandular and Filamentous Trichomes in Artemisia annua. BMC Plant Biology, 13, 220. http://dx.doi.org/10.1186/1471-2229-13-220

[32] Laughlin, J.C. (1994) Agricultural Production of Artemisinin-A Review. Transactions of the Royal Society of Tropical Medicine and Hygiene, 88, 21-22. http://dx.doi.org/10.1016/0035-9203(94)90465-0

[33] East African Botanicals Limited, EABL (2005) Growers Production Manuals for Artemisia annua. 12-123.

[34] Dharm, J.C., Ajay, M.K., Gupta, M., Anil, S.K., Ram, V.K. and Ajai, G.P. (1996) Isolation of High ArtemisininYielding Clones of Artemisia annua. Phytochemistry, 43, 993-1001. http://dx.doi.org/10.1016/S0031-9422(96)00369-X

[35] Sushil, K., Gupta, S.K., Poorinima, S., Pratima, B., Gupta, M.M., Digvijay, S., Gupta, A.K., Govind, R., Shasany, A.K. and Srikant, S. (2004) High Yields of Artemisinin by Multi-Harvest of Artemisia annua Crops. Industrial Crops and Products, 19, 77-90. 